\title{
Psychiatric Illnesses among the Patients Admitted for Self-poisoning in a Tertiary Care Hospital of Nepal
}

\author{
Ajay Risal, ${ }^{a^{*}}$ Pushpa Prasad Sharma, ${ }^{a}$ Rajkumar Karki ${ }^{\mathrm{b}}$ \\ ${ }^{a}$ Department of Psychiatry, Dhulikhel Hospital, ${ }^{b}$ Department of Forensic Medicine \\ Kathmandu University School of Medical Sciences (KUSMS), Dhulikhel, Kavre, Nepal
}

\author{
Accepted on \\ January $18^{\text {th }}, 2013$

\section{DOI Name} \\ 10.3126/jaim.v2i1.7630 \\ Keywords \\ Psychiatric illness, self-poisoning, Nepal

\section{Citation} \\ Risal A, Sharma PP, Karkib R. Psychiatric Illnesses \\ among the Patients Admitted for Self-poisoning in a \\ Tertiary Care Hospital of Nepal. Journal of Advances \\ in Internal Medicine 2013;02(01):10-3.
}

\begin{abstract}
Background and Aims- Self-poisoning is the commonest mode of suicide in our part of the world. Patients attempting suicide by self-poisoning usually land up in the Emergency. They are admitted for management of medical complications and subsequently referred to Psychiatry for evaluation of possible Psychiatric illnesses. The aim of this study was to explore the patterns of psychiatric illnesses in the patients admitted for self-poisoning in a tertiary care center in Nepal.
\end{abstract}

Methods- The study population included those patients who were admitted and being managed for self-poisoning and brought for psychiatric evaluation during the period of one year (1 $1^{\text {st }}$ June 2011- 30 th June 2012) at Dhulikhel Hospital, Nepal. Each patient underwent a detailed psychiatric evaluation by a consultant psychiatrist once they were medically stable. Details including sociodemographic data, psychiatric diagnosis, and treatment offered and outcome was tabulated and analyzed using SPSS-16.

Results- Among the total patients ( $N=100), 43$ were in the age group 21-40 years, median age being 27.5. There was almost equal gender distribution. Majority was of Mongolian ethnicity, homemaker by occupation and married. More than $90 \%$ were single-attempters, suicidal attempt using organophosphorus compounds. Almost 50\% had depression; family dispute (19\%) and marital disharmony (17\%) were the most common psychosocial precipitant.

Conclusion- Patients with history of self-poisoning are commonly brought to the Emergency Department of any tertiary care hospital. It is widely prevalent on younger age group. It is usually by the use of Organophosphorus compound in our setting and most commonly associated with depression. Hence, psychiatric care is essential for these patients.

\section{INTRODUCTION}

Self-poisoning has been considered to be the act of intentional self administration of more than the prescribed dose of any drug, including the non-ingestible substances, as well as the overdose of recreational drugs and alcohol intoxication. ${ }^{1}$ It is the commonest mode of attempting suicide; hence considered to be the major medical and social problem. ${ }^{2,3}$ It is also of great public health importance because the risk of completed suicide is very high for those with history of voluntary self poisoning even if they do not have any diagnosable psychiatric disorder. ${ }^{4}$ Recent literature has shown its grave picture in society estimating that one million people die from self poisoning each year equating to one every 40 seconds. ${ }^{5}$

Self poisoning has been found to be more common among the young adults not only in the Western European setting but also in our part of the world. ${ }^{2-5,6-8}$ A study done at a National level Hospital in Kathmandu concluded that suicide among young adults was associated with both the individual and psychosocial parameters such as relationship issues, unemployment, insufficient education as well as alcohol and drug misuse and it has been further escalating on exposure to stress. ${ }^{9}$

These people who attempt self-poisoning are usually brought to the emergency department for initial management of their clinical symptoms before being referred for specialty care. Hence, studies show major bulk of Emergency patients in any hospital is taken by self poisoning cases. ${ }^{10}$

It has also been shown in most of the National and International studies that most of these patients have a history of mental illness; the commonest diagnosis being depression which is usually followed by personality disorder alone or comorbid with other psychiatric illnesses. ${ }^{6,8,11}$

Keeping these facts and figures in mind, we intended to conduct a study aiming to analyze the patterns and determinants of psychiatric illnesses in the patients admitted for self-poisoning in a tertiary care hospital.

\section{METHODS}

This cross-sectional descriptive study based on the interview of the patients referred to the Department of Psychiatry at Dhulikhel Hospital (Kathmandu University Hospital) was initiated after getting approval from the Institutional Review Committee at Kathmandu University School of Medical Sciences (KUSMS).

The study population included all those patients who were admitted and being managed for self-poisoning and brought for psychiatric evaluation during the period of one year ( $1^{\text {st }}$ June 2011- $30^{\text {th }}$ June 2012). Each patient underwent a detailed psychiatric evaluation by a consultant psychiatrist once they were medically stable. Psychiatric diagnoses were considered as per ICD-10 criteria and patients were managed with

\footnotetext{
* Corresponding author

Dr. Ajay Risal

Psychiatrist/Lecturer

Dhulikhel Hospital, Kathmandu University Hospital

Kathmandu University School of Medical Sciences, P.O. BOX No. 11008

Kathmandu, Nepal. Dhulikhel, Kavre, Nepal

E-Mail-drajayrisal@gmail.com
} 
pharmacological / non-pharmacological measures. The factors related to suicide (intentionality and lethality) were assessed during the interview and mental status examination of the patients.

There were total 100 patients with history of self-poisoning referred from Medicine or Emergency Department and evaluated in Psychiatry Department during the whole study period. Details of these patients including socio-demographic data, psychiatric diagnosis considered, treatment offered and outcome was tabulated and analyzed using SPSS-16.

\section{RESULTS}

Among the total 14181 patients admitted in the Hospital throughout the study period, 100 were admitted for self-poisoning comprising $0.7 \%$ of total hospital admission. Similarly, $0.7 \%$ of the total 12765 patients seen in Emergency and $2.7 \%$ of the total 3653 patients seen in Psychiatry had history of self-poisoning.

As shown in the figure 1, most of the self-poisoning cases were seen in the three months, June to August 2011 showing the summer predominance.

\section{Figure 1. Monthwise distribution of the cases with self poisoning}

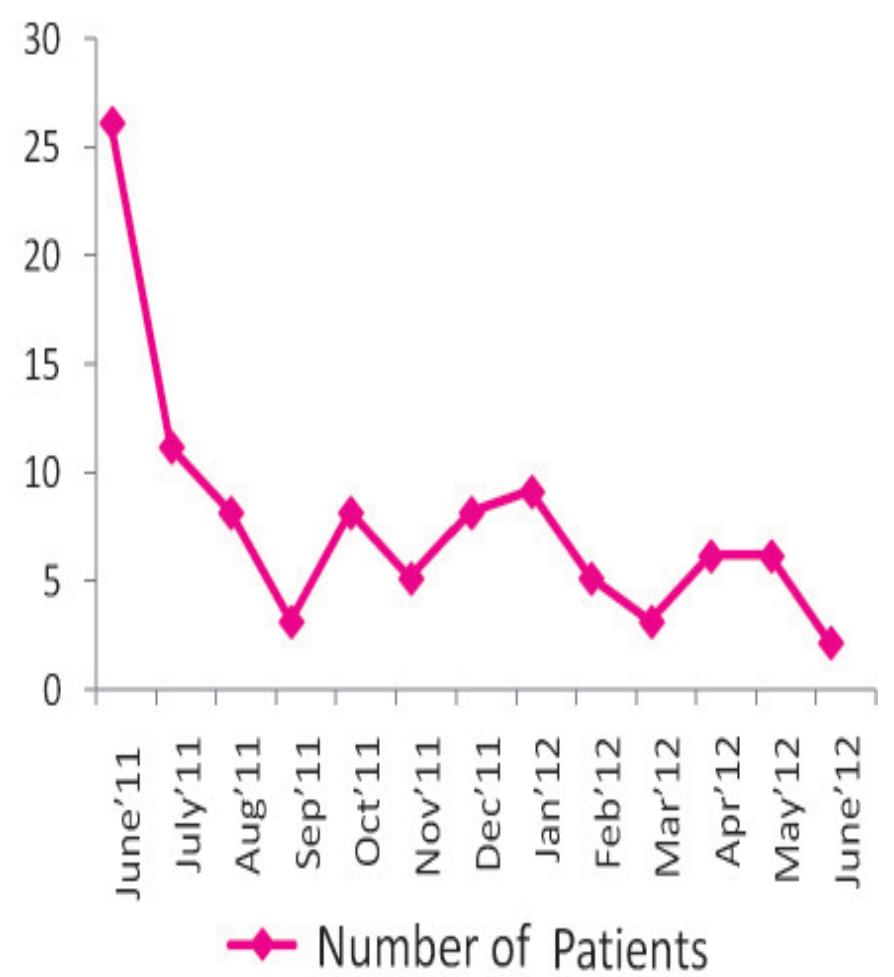

As shown in Table 1, most of the patients were in the age group of 2140 years; the median age being 27.5. There was almost equal gender distribution. More than $30 \%$ of them were of the Mongolian origin. Around $29 \%$ were homemakers, followed by farmers and students occupying 1 quarter each in the occupational status. Above $60 \%$ of the total sample population were married.

Table 2 reveals the factors related to poisoning among the sample population. Only $5 \%$ had multiple attempts in poisoning; $95 \%$ of them were first attempters. Almost all (92\%) attempts were suicidal. More than $80 \%$ used pesticides as the means of self-poisoning; Organophosphorus compound was the most common pesticide used (95\%). Only 32\% consumption was along with alcohol. Almost $73 \%$ had moderate degree of intentionality and $68 \%$ had high degree of lethality in suicide attempt.
Table 1. Distribution of socio-demographic factors in the cases with self-poisoning

\begin{tabular}{lc}
\hline Variables & $\begin{array}{c}\text { Frequency } \\
\text { Number (\%) }\end{array}$ \\
\hline Age group (Years) & \\
O-20 & $30(30)$ \\
$21-40$ & $43(43)$ \\
$41-60$ & $23(23)$ \\
$>=61$ & $4(4)$ \\
Median Age & \\
Sex & 27.5 \\
Male & \\
Female & $49(49)$ \\
Caste/ Ethnic group & $51(51)$ \\
Brahmin & \\
Chhetri & $17(17)$ \\
Newar & $23(23)$ \\
Mongolian & $16(16)$ \\
Terai/ Madhesi & $31(31)$ \\
Dalit/ Disadvantaged & $2(2)$ \\
Occupational status & $11(11)$ \\
\hline Farmer & \\
Homemaker & $25(25)$ \\
Business & $29(29)$ \\
Students & $3(3)$ \\
Others & $25(25)$ \\
Unemployed & $7(7)$ \\
Marital status & $11(11)$ \\
Single & \\
Married & $31(31)$ \\
Widow & $63(63)$ \\
Tale Distibution & $6(6)$ \\
\hline
\end{tabular}

Table 2. Distribution of poison related factors in the cases with selfpoisoning

\begin{tabular}{lc}
\hline Variables & $\begin{array}{c}\text { Frequency } \\
\text { Number (\%) }\end{array}$ \\
\hline Number of attempts & \\
\hline Single & $95(95)$ \\
Multiple & $5(5)$ \\
Mode of self-poisoning & \\
\hline Suicidal & $92(92)$ \\
Accidental & $8(8)$ \\
Type of Poison & \\
Pesticides & $84(84)$ \\
Prescription Drugs & $2(2)$ \\
Others & $11(11)$ \\
Unknown & $3(3)$ \\
Type of Pesticide (N=84) & \\
Organophosphorus & $80(95.2)$ \\
Others & $4(4.8)$ \\
Consumption with Alcohol & \\
\hline Yes & $32(32)$ \\
No & $68(68)$ \\
Intentionality of Suicide (N=92) & \\
High & $17(18.5)$ \\
Moderate & $67(72.8)$ \\
Low & $8(8.7)$ \\
Lethality of Suicide ( $\mathbf{N = 9 2 )}$ & \\
High & $58(68)$ \\
Moderate & $26(28.3)$ \\
Low & $8(8.7)$ \\
\hline
\end{tabular}


Table 3 shows the psychosocial factors related to self-poisoning. Almost $50 \%$ of the attempters had Depression (with or without Dysthymia); around $25 \%$ had personality disorder (alone or comorbid).

Table 3. Distribution of psychosocial factors among the cases with selfpoisoning

\begin{tabular}{|c|c|}
\hline Variables & $\begin{array}{l}\text { Frequency } \\
\text { Number (\%) }\end{array}$ \\
\hline \multicolumn{2}{|l|}{ Psychiatric Diagnoses } \\
\hline Psychotic spectrum disorder & $2(2)$ \\
\hline Depression \& Dysthymia & $46(46)$ \\
\hline Anxiety disorder & $1(1)$ \\
\hline Personality disorder & $23(23)$ \\
\hline Substance use disorder & $18(18)$ \\
\hline Undiagnosed & $10(10)$ \\
\hline \multicolumn{2}{|l|}{ Comorbid diagnoses ( $N=94)$} \\
\hline None & $52(55.3)$ \\
\hline Psychiatric & $14(14.9)$ \\
\hline Medical & $12(12.8)$ \\
\hline Both & $16(17)$ \\
\hline \multicolumn{2}{|l|}{ Past Psychiatric Illnesses } \\
\hline Yes & $25(25)$ \\
\hline No & $75(75)$ \\
\hline \multicolumn{2}{|c|}{ Psychosocial Precipitating factors } \\
\hline Marital disharmony & $17(17)$ \\
\hline Family dispute & $19(19)$ \\
\hline Love failure & $11(11)$ \\
\hline Death of loved ones & $6(6)$ \\
\hline Economic loss & $15(15)$ \\
\hline Chronic illnesses & $1(1)$ \\
\hline Exam failure & $14(14)$ \\
\hline Others & $1(1)$ \\
\hline None identified & $16(16)$ \\
\hline
\end{tabular}

Almost $20 \%$ had substance use disorder (mostly alcohol) while $10 \%$ did not fulfill any diagnostic criteria for psychiatric illnesses. A quarter of the sample population had positive past psychiatric illnesses. Regarding the psychosocial precipitating factors, almost $20 \%$ had some degree of family dispute, followed by marital disharmony (17\%), economic loss (15\%), exam failure (14\%) and love failure (11\%). In $16 \%$ of the situation, no significant precipitating factors could be recognized.

On analysis of the treatment related factors as shown in Table 4, almost one-third of them were admitted at Intensive Care Unit.

Table 4. Distribution of treatment related factors

\begin{tabular}{lc}
\hline Variables & $\begin{array}{c}\text { Frequency } \\
\text { Number (\%) }\end{array}$ \\
\hline Place of Admission & $62(62)$ \\
ICU & $38(38)$ \\
Ward & \\
Pharmacological treatment given (N=91) & \\
Antidepressants & $40(44)$ \\
Antipsychotics & $15(16.5)$ \\
Benzodiazepines & $1(1.1)$ \\
Combined & $35(38.5)$ \\
& \\
Outcome & \\
Recovered & $97(97)$ \\
Expired & $3(3)$ \\
\hline
\end{tabular}

More than $40 \%$ received antidepressants; while almost $40 \%$ received combination psychotopics. Only 3 of the total sample population expired during the course of treatment at hospital; all of them had consumed Aluminium Phosphide compound.

\section{DISCUSSION}

Most of the cases with self-poisoning are associated with suicide. ${ }^{2-4}$ Most of them are found to be having some psychiatric illnesses. ${ }^{6,8,11}$ Keeping in mind the findings in the literature not only among the Western population, but also that from our own set up, we intended to conduct this study in order to document the possibility of psychiatric illnesses and psychosocial precipitants among those patients attempting self-poisoning and receiving variety of treatment over a period of one year in our tertiary hospital setting.

Analyzing the socio-demographics of our sample population, we found most of the attempters were in their third to fifth decade of life. This finding well correlated with almost all the studies we came across; i.e., studies done at Greece, ${ }^{10}$ South Africa, ${ }^{12}$ India, ${ }^{3,8}$ and Nepal. ${ }^{6}$ Increased prevalence of Suicide attempt among young might be related to both individual and socioeconomic parameters such as relationship among family members, unemployment, insufficient education, and alcohol and drug misuse as documented in other similar studies. ${ }^{3,9}$

The highest rates for drug overdoses were found for female attempters in all the studies; whether European, ${ }^{2,10}$ South African, ${ }^{12}$ Indian ${ }^{8}$ or Nepali; ${ }^{7}$ in contrast to our finding of almost equal gender distribution. This may be because of the clustering of youth (both male and female) population in our study.

Prescription drugs (Paracetamol, NSAIDS, Antidepressants and Benzodiazepines) were more commonly used in European countries; ; $13,14^{2}$ while it was organophosphate compound in India ${ }^{3}$ and Nepal. ${ }^{6,7}$ It has been shown in studies that as many as $30 \%$ of global suicide deaths may involve ingestion of pesticides; most commonly with the use of organophosphorus due to easy availability and lack of strict legislation in the rural and agricultural areas, in the South Asian countries. ${ }^{15,16}$

Other studies have also shown a considerable increase in drug intoxication cases during summer months as in our study. , 17,18 In our set up, it may be related to the agricultural season when there will be abundant use of pesticides in fields; they are stored in households and easily procured. It was well investigated during our own study done a year back in the similar set-up. ${ }^{19}$

A majority of the patients were first time attempters as seen in a recent study done in India. ${ }^{8}$ This may be due to memory or recall bias among the patients or stigma related to the act; or because of the cross-sectional nature of our Hospital based study.

Most cases have a history of mental illness mostly depression followed by personality disorder alone or comorbid with other psychiatric illnesses

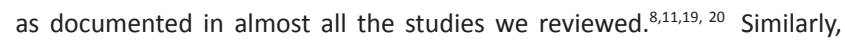
marital disharmony, family conflicts, economic hardships and family disputes were the major precipitating factors for the act in almost all the studies keeping with the findings in our study. ${ }^{2,8,10,18}$

Though our study was an attempt to document the psychosocial determinants of the hospitalized cases of self-poisoning, we had several limitations. Being a hospital based study of cross-sectional nature with a sample size of just 100 , our results cannot be generalized. Hence, large scale community study of prospective nature needs to be aimed upon in future to get a desired outcome. 


\section{CONCLUSION}

Self-poisoning cases are commonly brought to the Emergency Department of any tertiary care hospital. It is widely prevalent on younger age group. It is usually by the use of Organophosphorus compound in our setting and most commonly associated with depression. Hence, psychiatric care is essential for these patients.

\section{REFERENCES}

1. Harris L, Hawton K, Zahl D. Value of measuring suicidal intent in the assessment of people attending hospital following selfpoisoning or self injury. Br J Psychiatry 2005;186:60-6.

2. Tountas C, Sotiropoulos A, Skliros SA, et al. Voluntary selfpoisoning as a cause of admission to a tertiary hospital internal medicine clinic in Piraeus, Greece within a year. BMC Psychiatry 2001, 1:4. http://www.biomedcentral.com/1471-244X/1/4.

3. Priyalatha NR, Maity N, Shivamurthy MC. Intentional Poisoning as a Cause of Admission to Accident and Emergency in a Tertiary Care Hospital within a Year. Al Ame en J Med Sci 2011;396-400.

4. Christopher JB. Trends in self-poisoning: admissions to a Central London Hospital, 1991-1994. J R Soc Med 1997;90:496-8.

5. Hawton K, Harlingen KV. Suicide-The risk factors. Medical News Today 19th April 2009.Available at; http://www. medicalnewstoday.com/releases/146507.php.

6. Maskey A, Parajuli M, Kohli SC, et al. Scenario of poisoning cases in adults admitted in Manipal Teaching Hospital, Pokhara, Nepal. Nepal Journal of Medical Sciences 2012;1:23-6.

7. Bajracharya MR, Manandhar K, Deo KK, et al. Age and Gender Distribution in Deliberate Self-poisoning Cases. Post Graduate Medical Journal of Nepal Academy of Medical Sciences 2008;8:44-9.

8. Bansal PD, Barman R. Psychiatric Morbidity and the SocioDemographic Determinants of Deliberate Self Harm. Journal of Clinical and Diagnostic Research 2011;5:601-4.

9. Singh DP, Acharya RP. Pattern of poisoning cases in Bir Hospital. J Inst Med 2006;28:3-6.

10. Exiara T, Mavrakanas TA, Papazoglou L, et al. A prospective study of acute poisonings in a sample of Greek patients. Cent Eur J Public Health 2009;17:158-60.

\section{ACKNOWLEDGEMENT}

We would like to thank Mr. Kedar Manandhar, MPH, Lecturer, Department of Community Medicine for his assistance in statistical analysis and Ms. Yasoda Bajagain, CMA, Department of Psychiatry, KUSMS, Dhulikhel, Kavre, Nepal for helping in documentation.

11. Haw C, Hawton K, Houston K, et al. Psychiatric and personality disorders in deliberate self harm patients. $\mathrm{Br} J$ Psychiatry 2001;178:48-54.

12. Toit EH, Kruger JM, Swiegers SM, et al. The profile analysis of attempted-suicide patients referred to Pelonomi Hospital for psychological evaluation and treatment from 1 May 2005 to 30 April 2006. S Afr J Psychiatr 2008;14:20-5.

13. Milicevic G, Pric H: Self-poisonings with psychopharmacological agents in Zagreb. Hum Exp Toxicol 1991;10:305-9.

14. Dimakopoulou A, Rontos I, Spyropoulos I, et al. Preliminary observations during the first year of running of Psychiatric Consultation Services in the Regional General Hospital of Nikea "Damon Vasiliou". Encephalos 1989;26:168-72.

15. Ahmad M, Rahman FN, Ashrafuzzaman M, et al. Overview of organophosphorus Compound Poisoning in Bangladesh and medico legal aspects related to fatal cases. JAFMC 2009;5:41-5.

16. Gupta BD, Vaghela PC. Profile of fatal poisoning in and around Jamnagar. JIFM 2005;27:971-3.

17. Billis A, Tsirogiannis D, Vosnidis G, et al. Voluntary drug intoxications (Observations on 734 cases). Material Medical Greca 1978;61-5.

18. Bazas TH, Gemos G, Stefanis K, et al. Incidence of seasonal distribution and demographic characteristics of suicides in Greece. Materia Medica Greca 1978;6:38-46.

19. Risal A, Sharma PP. Psychiatric manifestations of patients admitted for intentional self harm. J Inst Med 2011;33:43-8.

20. Papamichael E, Pertesi E, Spiropoulos J, et al. First years of experience in consultation-liaison Psychiatry in Greece: Proc. of the 8th World Congress of Psychiatry, 262. 